\title{
About the whimsical relationship between technology and art
}

\begin{abstract}
The unpredictable equilibrium between technical and artistic points of view originated in our perception of the reality is discussed. We postulate a metastable "Whimsical Equilibrium" to confront both points of view, which includes an undetermined amount of uncertainty depending of our perception. The relation between technology and art is presented, through the branch of materials science called "Metallography", and the art activity called "Painting". Based on a metallographic example (an optical micrograph of a hypoeutectoid plain carbon steel), a clear distinction between an objective technical point of view and a subjective artistic consideration was made.
\end{abstract}

Keywords: metastable equilibrium, perception, technology and art, metallography, painting
Volume I Issue 2 - 2017

\author{
Oswaldo Hilders \\ Department of Physical Metallurgy, Central University of \\ Venezuela, Venezuela
}

\begin{abstract}
Correspondence: Oswaldo Hilders, Department of Physical Metallurgy, Central University of Venezuela, Venezuela, Tel +58
\end{abstract} 2I23725230,Email ohilders@hotmail.com

Received: August 28, 2017 | Published: September 12, 2017

\section{Introduction}

The interpretation of the relation between technology and art has evolved over the years. Technical difficult concepts representing barriers to the understanding can be overcome with the participation of many areas of our current technology. Frequently, those areas that we used to call subjective must be taken into account too. The basic difference between art and technology is represented by the subjectivism surrounding the artist's creation. An example which represents this basic difference is that of a civil engineer and an abstract painter. On the one hand, a civil engineer needs to fully understand the steps to create a bridge, a building, or any other bulk engineering construction, which must match certain standards. On the other hand, a painter does not place limits in principle, on when or how an artwork must be created. The history of our civilization has been plenty of thinkers who tried to unravel the true significance of the relation between art and technology. Today more than ever before, the opportunity is clear to disclose this relation, based on the great accessibility to information, the development of technical tools to understand theoretical concepts etc. In the present work we attempt to make some progress on the interpretation of the relationship between technology and art. Our central problem is to make clear that an object of the real world can be perceived technically or artistically, although very frequently neither one nor the other totally prevails for a common human being. Here, a short opinion about the relation between technology and art is presented through the branch of materials science called "Metallography" and the art activity called "Painting".

Metallography is the scientific study of the microstructure of metals and its alloys. It encompasses the observation and analysis of the distribution of phases, impurities, etc., as well as the determination of the corresponding chemical composition and atomic structure. Analogous procedures are normally applied to any other material. Once the complete metallographic study of certain alloy is finished, and a photograph of its microstructure is taken, how then could we tell whether this microstructure should have a definite significance? For a metallurgical engineer, the significance is related with the future application of the alloy, according with the characteristics of the revealed microstructure, which in turn, depends on the previous experience with this particular alloy. For an artist the microstructure of the alloy could have multitude of meanings.

Fractal theory maybe constitutes the best example of how technology and art can be merged to produce a combined perception of the reality. Mandelbrot, ${ }^{1-3}$ through his creation of fractals, has the responsibility of an enormous contribution to the knowledge, not just in mathematics but to the science as a whole. In the particular area of materials science, a basic review of the fundamentals of the analysis of fractal characteristics in metals was published by Hornbogen ${ }^{4}$ and still applies. As this review accurately describes the main part of the metal's microstructures, it can be used as a starting point of the current studies of fractal defects in metals and its alloys. A few examples of recently published technical fractal related papers in metallurgy and materials science are presented here. Hilders et al., ${ }^{5}$ using conventional metallography, image processing techniques and scanning electron microscopy, showed the influence of the fractal dimension of the grain microstructure and the fractal dimension of the tension fracture surface, on the strength of AISI 316L austenitic stainless steel, through the Hall-Petch relation. Losa et al., ${ }^{6}$ emphasize the importance of some basic concepts in fractal theory and Sun et al., ${ }^{7}$ successfully applied a fractal method to solve an industrial problem related to the tracking prediction of the exit strip thickness in a hot rolling mill. A great contribution to the study of fractals in general, and to its relation with art and science has been made through the years by Taylor. ${ }^{8-10}$ Although just 3 specific works of this author have been referred here, his fractal related contributions encompass: statistical comparison of painting techniques, aesthetic and neuroscientific approaches to the arts, art and science of hyperbolic tessellations, the fractal geometry of the brain, the authentication of paintings using fractal geometry, and much more. It is hoped in the years to come, that an increased development of the relation between technology and art (or indistinctly, between science and art) can be achieved.

\section{Materials and methods}

The present work was based on an unpublished optical micrograph (Figure 1A), taken previously by the author. The material was a hypoeutectoid plain carbon steel (AISI 1020), which was received from a commercial supplier. A sample of this steel was annealed 
for $30 \mathrm{~min}$ at $850^{\circ} \mathrm{C}$ and furnace cooled to room temperature. After the heat treatment, a metallographic preparation was made to reveal the ferrite pearlite microstructure. For the purpose of the present work, the Figure 1A was duplicated and several artificial "nonmetallic inclusions" were added to the original photograph of the microstructure (Figure 1B).

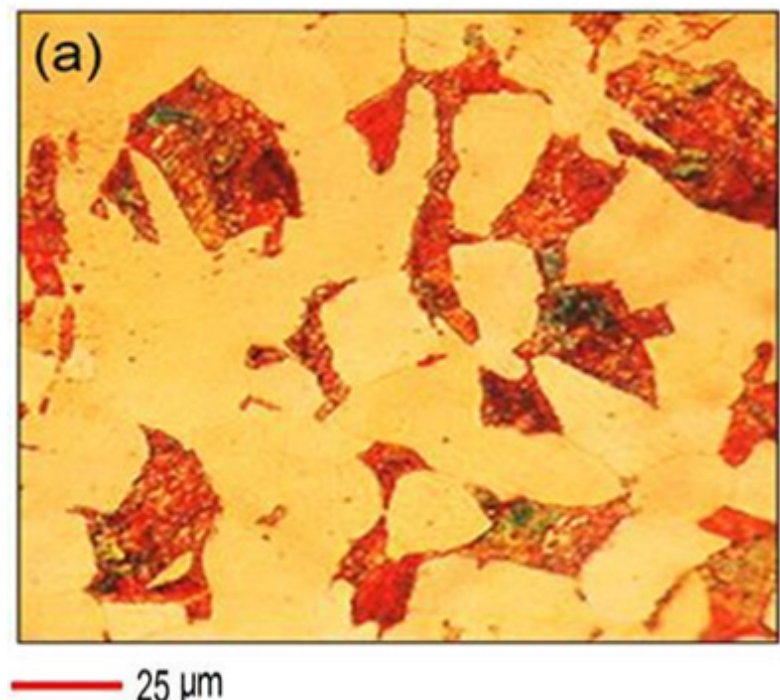

Figure IA Optical micrograph of the ferrite-pearlite microstructure of the studied steel (ferrite: Light phase, pearlite: dark phase).

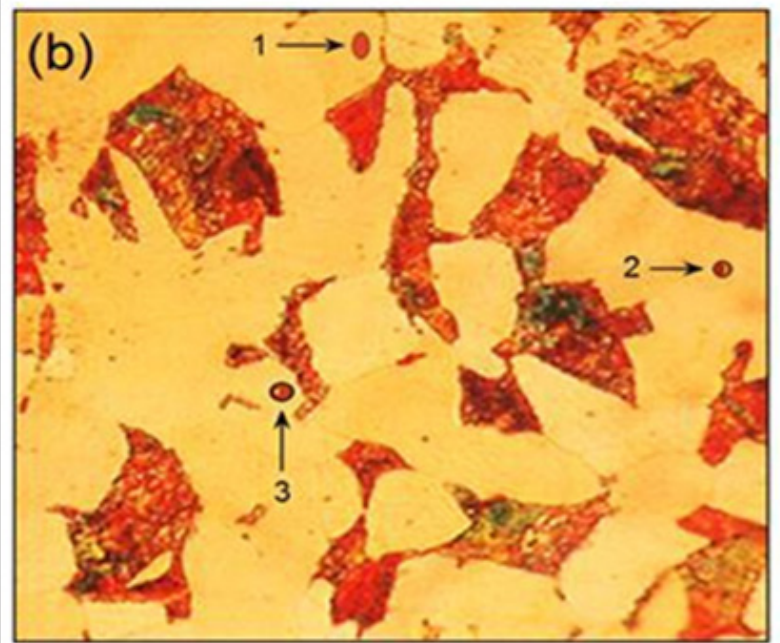

Figure IB The same microstructure with some artificially added "nonmetallic inclusions" at I, 2 and 3 .

\section{Results and discussion}

In Figure 1A, the microstructure of the analyzed steel is shown. Whichever direction we look in this Figure, the function of the ferrite pearlite microstructure from an engineering point of view remains the same. If this picture is considered an abstract painting, then thousands of subjective explanations about its significance can be suggested by many people. These different opinions can be explained on the basis of the vagueness related to our absolute ignorance about the painter's mind, otherwise we should be more or less able to know what the painter wanted to express.
On the other hand, Figure 1B shows a microstructure identical to the one shown in Figure 1A, with a low amount of artificially added "nonmetallic inclusions" at points 1,2 and 3. If it were the original microstructure, with real and dangerous inclusions, a wrong mechanical behavior of the steel can lead to a catastrophic failure of the piece made with it, although common people will remain blind to the subtle changes of the microstructure if it is seen as an abstract painting. In other words, for an external viewer, this almost unnoticeable change in this "artwork" is unlikely to generate a change in his original opinion about its significance.

From the above, although a piece of engineering can be considered simultaneously a piece of art, we can envisage that for an average human being it could be difficult to consider that both points of view are equally valid quantitatively speaking. Which point of view prevails depends of the characteristics of a particular viewer.

We can postulate the existence of a metastable equilibrium between the perceptions of what is real for us as a function of a specific scientific knowledge, and what can be taken as a mere pleasant or discordant artistic picture with a scarce quantitative significance. This kind of equilibrium defines our sense of reality, which includes a variable amount of uncertainty depending of our vision: From a point of view of an artist, or from a point of view of a technician. We propose to call this particular metastable equilibrium "Whimsical Equilibrium".

\section{Conclusion}

The relation between technology and art was presented through the branch of materials science called "Metallography", and the art activity called "Painting". Based on a metallographic example (an optical micrograph of a hypoeutectoid plain carbon steel), a clear distinction between an objective technical point of view and a subjective artistic consideration was made. Then, we defined a metastable equilibrium between technical and artistic points of view, which depends on our particular sense of reality. We call this equilibrium "Whimsical Equilibrium”, as its very nature is not predictable at all.

\section{Acknowledgements}

None.

\section{Conflict of interest}

The author declares no conflict of interest.

\section{References}

1. Mandelbrot BB. How long is the coast of britain? Statistical selfsimilarity and fractional dimension. Science. 1967;156(3775):636-638.

2. Mandelbrot BB. The Fractal Geometry of Nature. 1st ed. Freeman WH, USA; 1982.

3. Mandelbrot BB, Passoja DE, Paullay AJ. Fractal character of fracture surfaces of metals. Nature. 1984;308(5961):721-722.

4. Hornbogen E. Fractals in microstructure of metals. International Materials Reviews. 1989;34(6):277-296.

5. Hilders OA, Zambrano N, Caballero R. Microstructure, strength and topography relations in AISI 316L stainless steel as seen through a fractal approach and the Hall-Petch law. International Journal of Metals. 2015;2015(ID 624653):10.

6. Losa GA, Ristanović Duš, Ristanović Dej, et al. From fractal geometry to fractal analysis. Appl Math. 2016;7(4):346-354. 
7. Sun L, Shao C, Zhang L. Dynamic tracking prediction control of exit strip thickness based on improved fractal. Metall Res Technol. 2017;114(4):1-15.

8. Taylor RP, Micolich AP, Jonas D. Fractal analysis of Pollock's drip paintings. Nature. 1999;399(6735):422.
9. Taylor RP. Ch 11, Fractal Expressionism-Where Art Meets Science. In: Casti J, Karlqvist A, editors. Art and Complexity. 1st ed. Elsevier, Amsterdam, The Netherlands; 2003. p. 117-144.

10. Taylor RP. Science and art: Emergence of patterns from nature's chaos, through parallels between Edward Lorenz and Yves Klein. Nonlinear Dynamics Psychol Life Sci. 2009;13(3):341-348. 